Corrigendum

\title{
Corrigendum to "Pulmonary Hypertension Secondary to Partial Anomalous Pulmonary Venous Return in an Elderly Patient"
}

\author{
Stefan Koester $\left(\mathbb{D}\right.$, Justin Z. Lee $\mathbb{D}^{D}$, and Kwan S. Lee $\mathbb{D}$ \\ University of Arizona, Tucson, AZ 85714, USA \\ Correspondence should be addressed to Kwan S. Lee; klee@shc.arizona.edu \\ Received 4 July 2019; Accepted 8 July 2019; Published 21 November 2019 \\ Copyright (C) 2019 Stefan Koester et al. This is an open access article distributed under the Creative Commons Attribution License, \\ which permits unrestricted use, distribution, and reproduction in any medium, provided the original work is properly cited.
}

In the article titled "Pulmonary Hypertension Secondary to Partial Anomalous Pulmonary Venous Return in an Elderly" [1], there was an error in the article's title where the word "Patient" should be added at the end of it. The updated title is shown above.

\section{References}

[1] S. Koester, J. Z. Lee, and K. S. Lee, "Pulmonary hypertension secondary to partial anomalous pulmonary venous return in an elderly," Case Reports in Cardiology, vol. 2016, Article ID 8609282, 4 pages, 2016. 


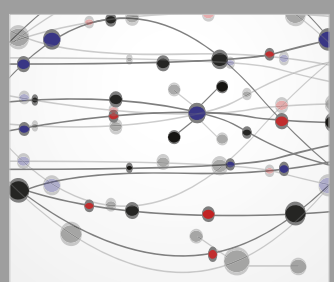

The Scientific World Journal
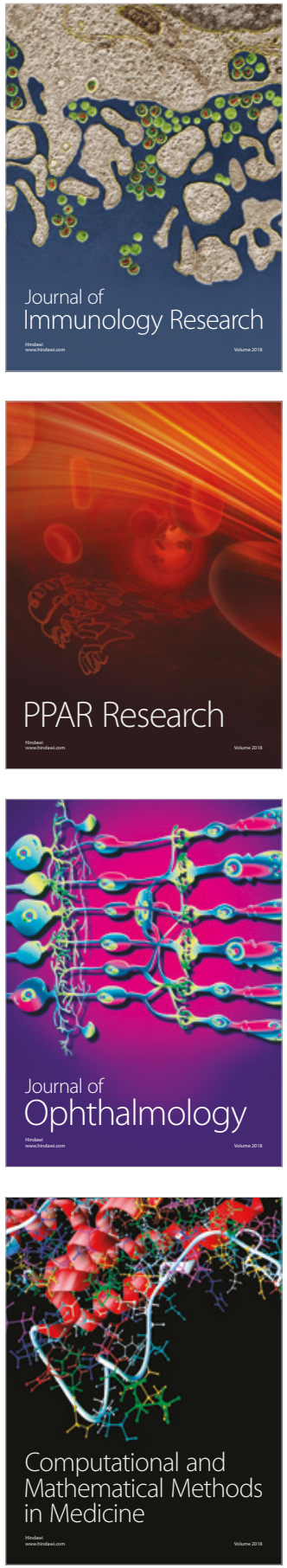

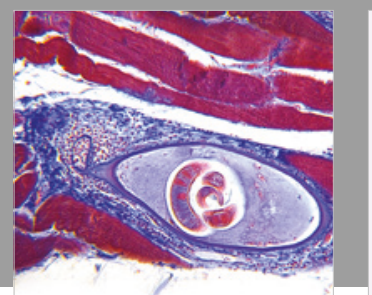

Gastroenterology Research and Practice

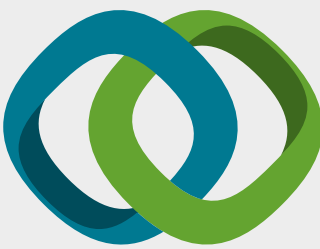

\section{Hindawi}

Submit your manuscripts at

www.hindawi.com
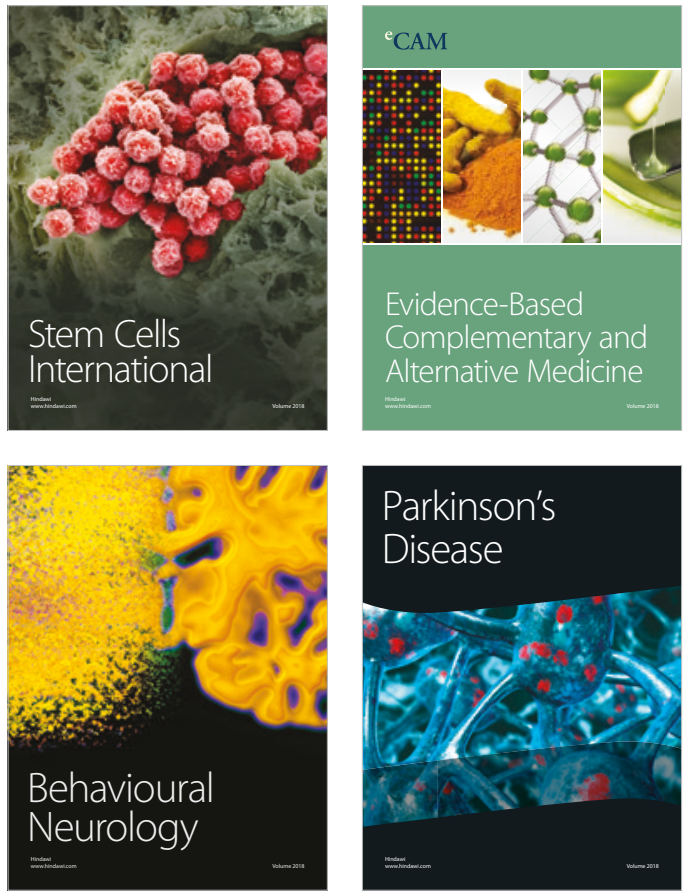

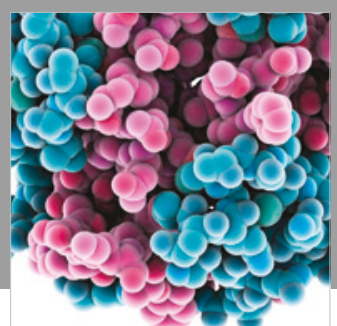

ournal of

Diabetes Research

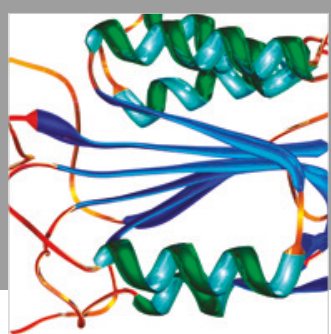

Disease Markers
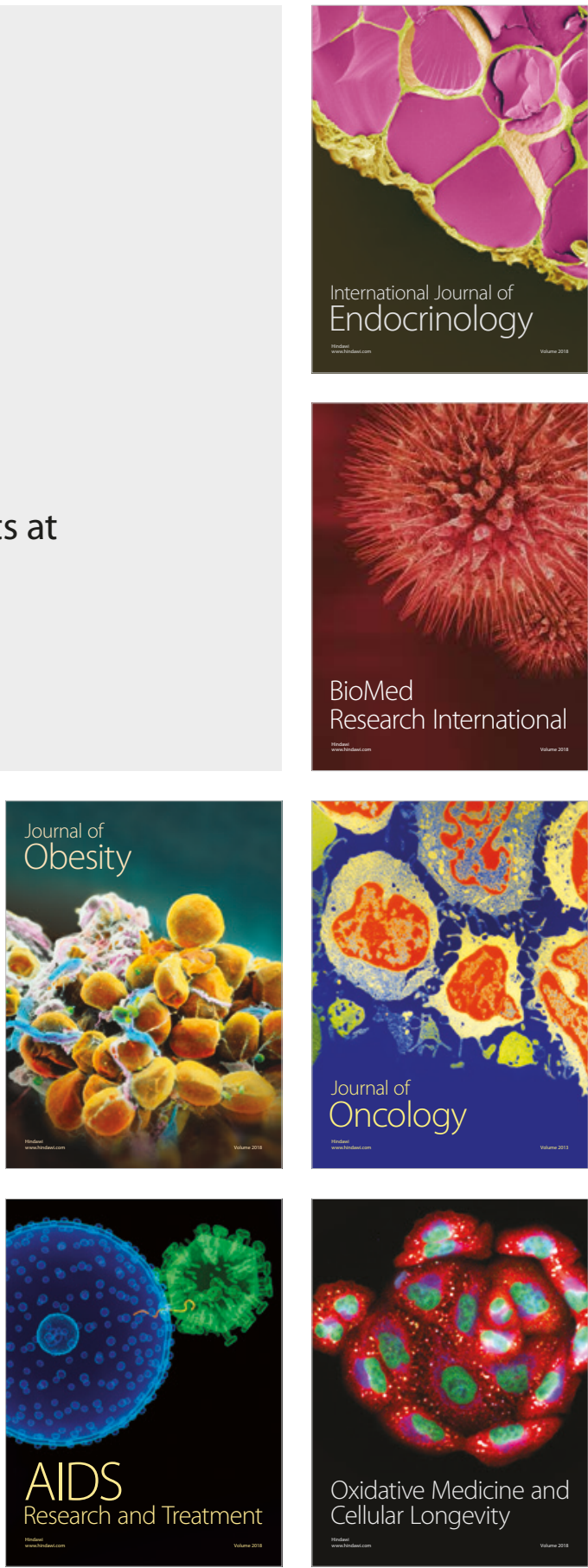